\title{
Transantral intraseptal sinuous canal
}

\author{
M.C. Rusu®, C. Bichir, A.D. Vrapciu \\ Division of Anatomy, Faculty of Dental Medicine, "Carol Davila" University of Medicine and Pharmacy, Bucharest, Romania
}

[Received: 27 November 2020; Accepted: 30 December 2020; Early publication date: 22 January 2021]

\begin{abstract}
The sinuous canal is an anatomically well-defined intramural canal of the maxillary sinus (MS) folded within the antral walls. Commonly, its first, infraorbital part, courses within the antral roof, while its second, transverse facial part courses below the infraorbital foramen within the anterior antral wall. While retrospective files of patients that were scanned in cone-beam computed tomography (CBCT) for different dental medical purposes were observed randomly, a peculiar variant of the sinuous canal was noticed and further documented. The respective canal origin was far posterior in the infraorbital groove and the canal coursed through the MS embedded within an incomplete oblique septum dividing the antrum into anterosuperior and posteroinferior chambers. Then the sinuous canal continued with the transverse facial segment. As the sinuous canal contains the superior anterior alveolar nerve and artery, major suppliers of the frontal teeth, it is recommended to document in CBCT a possible transantral, and not intramural, course of it, especially when surgical or endoscopic corridors through the MS are planned. (Folia Morphol 2022; 81, 1: 234-236)
\end{abstract}

Key words: superior anterior alveolar nerve, infraorbital nerve, infraorbital canal, maxillary sinus

\section{INTRODUCTION}

The canalis sinuosus (CS) diverts from the infraorbital canal (IOC) allowing passage for the anterior superior alveolar nerve (ASAN) and anterior superior alveolar artery (ASAA) that branch from the infraorbital neurovascular bundle $[8,9]$. Forming in the roof of the maxillary sinus (MS) and usually ending at the base of the anterior nasal spine, it has an anteromedial direction through the maxillary walls, passing inferior to the infraorbital foramen (IOF) [13].

The double curvature along the course of the canal is what attributed the term "sinousus" to its name. Usually, it tunnels from the IOC through the orbital floor (the primary segment of the CS) to reach the anterior antral wall where it takes a sharp turn downward and medial to reach the nasal lateral wall, in front of the anterior end of the inferior concha. From there it angles again, following the contour of the anterior nasal aperture, towards the anterior nasal spine [4].

Although its passage is described as a sinuous path folded to the maxillary walls all the way from the IOC to the anterior maxillary region, the CS can have a more direct path through a MS septum. To our knowledge, an intraseptal, transantral variant of the CS has not been reported before.

Taking into consideration the clinical implications of damaging the ASAN during surgical procedures such as Caldwell-Luc, sinus floor elevation, and antrostomy, surgical interventions in the posterior maxillary region require detailed knowledge of maxillary sinus anatomy and possible anatomical variations [6].

Address for correspondence: C. Bichir, DDS, PhD stud., Assist.Prof., Division of Anatomy, Faculty of Dental Medicine, "Carol Davila" University of Medicine and Pharmacy, 8 Eroilor Sanitari Blvd., RO-050474, Bucharest, Romania, tel: +40723628148 , e-mail: catalina.bichir@drd.umfcd.ro This article is available in open access under Creative Common Attribution-Non-Commercial-No Derivatives 4.0 International (CC BY-NC-ND 4.0) license, allowing to download articles and share them with others as long as they credit the authors and the publisher, but without permission to change them in any way or use them commercially. 


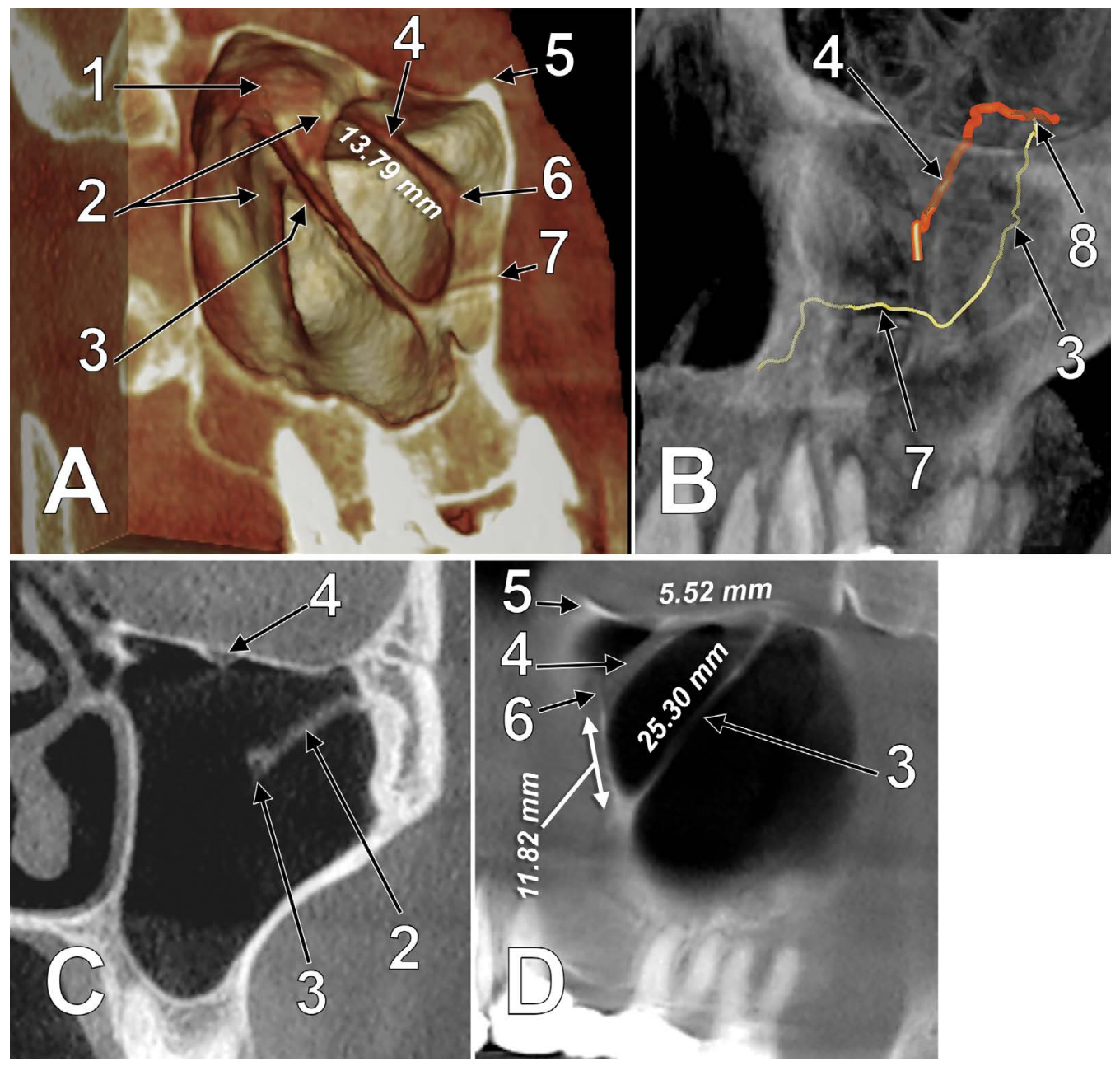

Figure 1. Transantral canalis sinuosus embedded within an incomplete intrasinus septum; A. Three-dimensional volume rendering, postero-infero-medial view of the left maxillary sinus; $\mathbf{B}$. Three dimensional volume rendering, anterior view of the left maxilla, digitally reconstructed canals; C. Planar coronal cut of the left maxillary sinus; D. Digital orthopantomogram of the left maxillary sinus; 1 - infraorbital groove; 2 incomplete oblique septum; 3 - transantral course of the first segment of the canalis sinuosus, from the infraorbital groove to the anterior antral wall; 4 - infraorbital canal; 5 - infraorbital margin; 6 - infraorbital foramen; 7 - intramural transverse facial segment of the canalis sinuosus; 8 - canalis sinuosus' origin from the infraorbital groove. Measurements were taken on sagittal cuts and applied in the figures.

\section{CASE REPORT}

During an evaluation on cone-beam computed tomography (CBCT) archived files, a unilateral transantral course of the CS was found in a 56-year-old female patient. As described in previous studies, the $C B C T$ patient file was scanned with an iCat CBCT machine (Imaging Sciences International; Hatfield, PA, USA) with the settings: resolution 0.250 pixels/inch, field of view $130 \mathrm{~mm}$, and image matrix size $640 \times 640$ pixels $[9,10]$. By using the iCatVision software, the $\mathrm{CBCT}$ data were exported as a single uncompressed DICOM file, which was further analysed using the Planmeca Romexis Viewer 3.5.0.R software. The patient had given written informed consent for all medical data to be used for research and teaching purposes, provided the protection of the identity is maintained.
The right side presented no abnormal pattern of the $C S$, and a single antral septum was noticed in the maxillary sinus. On the left side, endosinus anatomy was different (Fig. 1). Two antral septa were found, one attached to the sinus roof below the infraorbital groove (IOG), and another one below the first, that ended on the MS floor in the premolar area. Both septa were located in the same anatomical plane having an anteroinferior direction. A transantral course of the left IOC was found in the superior septum. Within the inferior septum, another canal coursed from the IOG, through the MS, to the anterior antral wall where it continued beneath the IOF with a transverse course. This was therefore assessed as CS with the first segment being equally transantral and intraseptal. 


\section{DISCUSSION AND CONCLUSIONS}

It is considered that the CS "has been little explored and many practitioners have no knowledge of its presence and location" [1] and that "many surgeons do not know much about this anatomical structure" [4].

The CS prevalence ranges between studies from $15.7 \%$ to $100 \%$, and in a recent CBCT study [1], it was found that only $54.14 \%$ of patients presented bilateral CS. This implies that although the CS is a well-described anatomical structure, its presence is not easily traceable.

Anatomical transantral passage is not uncommon knowledge, as it has been presented before for other structures like the IOC [2]. Still, to the authors' knowledge, a transantral variant of the CS has not been described yet. Even more peculiar, the canal is situated in the bony confinement of a septum, making it insidious to clinicians in the absence of a complex radiological investigation.

The maxillary sinus septa are of interest, especially when performing surgical procedures such as sinus lift [5] or even Le Fort I osteotomy [11]. These barriers of cortical bone can arise from the antral floor or walls as primary or secondary septa to partially or completely separate the sinus into two or more cavities [7]. As secondary septa appear based on progressive pneumatisation of the MS in edentulous patients, in this case, both septa that have been found could be regarded as primary ones.

In endonasal endoscopic approaches of transmaxillary-transantral surgical intervention routes, large portions of the medial antral wall, as well as other bony structures along the way, might be removed. The purpose is to gain access to the posterior maxillary sinus wall in the attempt of removing lesions in the pterygopalatine fossa [3] or to approach the Meckel's cave [12].

Because of it being featured as a small, poorly recognised bony canal, the CS usually gets acknowledged when postsurgical complications such as haemorrhage, pain, anaesthesia, and paraesthesia appear [4]. Therefore, in surgical procedure planning, the transantral variant of CS should be taken into account, and careful evaluation of three-dimensional radiological investigation of the antral septa is recommended.

\section{Conflict of interest: None declared}

\section{REFERENCES}

1. Aoki R, Massuda M, Zenni LT, et al. Canalis sinuosus: anatomical variation or structure? Surg Radiol Anat. 2020; 42(1): 69-74, doi: 10.1007/s00276-019-02352-2, indexed in Pubmed: 31606782.

2. Cârstocea L, Rusu MC, Pascale C, et al. Three-dimensional anatomy of the transantral intraseptal infraorbital canal with the use of cone-beam computed tomography. Folia Morphol. 2020; 79(3): 649-653, doi: 10.5603/ FM.a2019.0109, indexed in Pubmed: 31617577.

3. Cavallo L, Messina A, Gardner P, et al. Extended endoscopic endonasal approach to the pterygopalatine fossa: anatomical study and clinical considerations. Neurosurgical Focus. 2005; 19(1): 1-7, doi: 10.3171/foc.2005.19.1.6.

4. Gurler G, Delilbasi C, Ogut EE, et al. Evaluation of the morphology of the canalis sinuosus using cone-beam computed tomography in patients with maxillary impacted canines. Imaging Sci Dent. 2017; 47(2): 69-74, doi: 10.5624/isd.2017.47.2.69, indexed in Pubmed: 28680842.

5. Jung J, Park JS, Hong SJ, et al. Axial triangle of the maxillary sinus, and its surgical implication with the position of maxillary sinus septa during sinus floor elevation: a CBCT analysis. J Oral Implantol. 2020; 46(4): 415-422, doi: 10.1563/aaid-joi-D-18-00229, indexed in Pubmed: 32315428.

6. Krennmair G, Ulm C, Lugmayr H. Maxillary sinus septa: incidence, morphology and clinical implications. J Craniomaxillofac Surg. 1997; 25(5): 261-265, doi: 10.1016/ s1010-5182(97)80063-7, indexed in Pubmed: 9368861.

7. Maestre-Ferrín L, Galán-Gil S, Rubio-Serrano M, et al. Maxillary sinus septa: a systematic review. Med Oral Patol Oral Cir Bucal. 2010; 15(2): e383-e386, doi: 10.4317/ medoral.15.e383, indexed in Pubmed: 19767706.

8. Rusu MC, lacov-Crăițoiu MM, Săndulescu M, et al. Constant features of the adult maxillary bone in the site of the premaxillary suture: the sutura notha, Macalister's foramina, Parinaud's canal, and the second angle of the canalis sinuosus of Wood Jones. Rom J Morphol Embryol. 2019; 60(4): 1097-1103, indexed in Pubmed: 32239084.

9. Rusu MC, Săndulescu M, Bichir $C$, et al. Combined anatomical variations: The mylohyoid bridge, retromolar canal and accessory palatine canals branched from the canalis sinuosus. Ann Anat. 2017; 214: 75-79, doi: 10.1016/j. aanat.2017.07.006, indexed in Pubmed: 28823708.

10. Rusu MC, Sava CJ, Ilie AC, et al. Agger nasi cells versus lacrimal cells and uncinate bullae in cone-beam computed tomography. Ear Nose Throat J. 2019; 98(6): 334-339, doi: 10.1177/0145561319840836, indexed in Pubmed: 31012345

11. Samsudin AbR, Qabbani A, Wahbi S. Le fort i osteotomy complicated by presence of maxillary sinus septa. J Craniofac Surg. 2020 [Epub ahead of print], doi: 10.1097/ SCS. 0000000000006650 , indexed in Pubmed: 32604301.

12. Van Rompaey J, Suruliraj A, Carrau R, et al. Meckel's cave access: anatomic study comparing the endoscopic transantral and endonasal approaches. Eur Arch Otorhinolaryngol. 2014; 271(4): 787-794, doi: 10.1007/s00405013-2581-2, indexed in Pubmed: 23771278.

13. von Arx T, Lozanoff $S$. Anterior superior alveolar nerve (ASAN). Swiss Dent J. 2015; 125(11): 1202-1209, indexed in Pubmed: 26631255. 